\title{
Migración e identidad: familias hispanoamericanas en Porto Alegre (Brasil)
}

\author{
Jorge Castellá Sarriera* \\ Pontifícia Universidade Católica do Rio \\ Grande do Sul \\ María Piedad Rangel M. \\ Universidade Regional do Alto Uruguai e \\ das Missões-FW. Brasil

Ana Paula Oliveira
Julia Hermel
Carolina Hofstaetter
Becarias de Iniciación Científica
CNPq. PUC-RS.

Recibido: octubre 15 de 2004

Revisado: octubre 26 de 2004 Aceptado: noviembre 28 de 2004

\section{Resumen}

Este artículo presenta un estudio realizado con 11 familias latinoamericanas inmigrantes en la Gran Porto Alegre $^{1}$, Brasil. Su objetivo fue dar cuenta de los procesos identitarios a través de las dimensiones personal, cultural, étnica-racial y nacional de estas familias. Para ello, se realizaron entrevistas semiestructuradas que fueron analizadas a través del método de análisis de contenido, a partir de categorías a priori. Se encontró que estas familias viven procesos aculturativos de integración cultural en los que mantienen costumbres de su país de origen y se adaptan al país de acogida. Únicamente una de las familias entrevistadas presenta asimilación cultural, caracterizada por la pérdida de la cultura de origen.

Palabras clave: familia, migración, aculturación, identidad.

\section{Abstract}

This article presents a study made with 11 immigrant latin-american families in Gran Porto Alegre (Brazil); its purpose was to take account of identitary processes

\footnotetext{
* Correspondencia: Jorge Castellá Sarriera, Pontifícia Universidade Católica do Rio Grande do Sul. Predio 11. Nono andar sala 29 Avenida Ipiranga, 6681 CEP 90619-900 Porto Alegre - RS Brasil.

1 Porto Alegre es la capital de Estado de Rio Grande do Sul, siendo considerada Gran Porto Alegre una área metropolitana que está conformada por varios municipios cercanos a la ciudad.
} 
trough these families personal, culture, racial ethnic and national dimensions. Semi-structured interviews were made, which were analyzed through the content analysis method, from a priori categories. The results showed that theses families live non-cultural processes of cultural integration, in which they maintain their origin country customs and they adapt to the country they now live. Only one of the interviewed families presents cultural assimilitation, characterized by the loss of its origin culture.

Index terms: family, migration, non-culture, identity.

\section{Introducción}

Las migraciones, en cuanto proceso social, pueden ser entendidas como un complejo fenómeno que envuelve cambio no solamente de dirección (después de cruzar la frontera de una unidad administrativa), sino de toda una serie de contactos socioculturales del individuo, en todas las áreas de su vida. El estrés psicológico inherente al cambio vuelve al inmigrante particularmente vulnerable a los riesgos de morbilidad diferencial en su nuevo ambiente, más aún si ese ambiente se desplaza hacia un área densamente urbanizada, en donde enfrentará riesgos ambientales diferentes de aquellos experimentados antes de emigrar (Mota, Franco y Motta, 1999).

De acuerdo con Klein (1999), para entender el fenómeno social de la inmigración se deben tener en cuenta dos tipos de factores: los de expulsión y los de atracción, ambos con múltiples matices. En tesis, pocas personas poseen un deseo absolutamente inmanente de emigrar, de abandonar su casa o entorno social. Emigran normalmente por razones de manutención de la calidad de vida, en un intento de vivir de forma tradicional como lo hacían en sus comunidades de origen.

No obstante, normalmente existen algunos factores que imposibilitan vivir como lo esperado o deseado en sus comunidades de origen, buscando entonces un cambio físico no siempre acompañado de deseo de cambio cultural. Los principales factores de expulsión de un país son de origen económico, nacional -como ocurre con las mino- rías étnicas- y religioso, cuando son éstos minoritarios o no reconocidos (Klein, 1999).

El más complejo de estos niveles es el económico. Aunque en el período de las grandes migraciones haya sido bien establecido por la historiografía, se cree que esta caracterización de los factores económicos de expulsión no sea válida para la comprensión de la determinación de estos actores hoy. Tales factores económicos de expulsión pueden ser caracterizados por: acceso a la tierra o empleo/alimentación, variación de la productividad agrícola y/o industrial y número de hijos o dependientes (Klein, 1999).

Los factores de atracción, principalmente los que operaron en los grandes movimientos migratorios de la historia, fueron la abundancia de tierras y la baja densidad demográfica y/o gran oferta de trabajo. En América, esto fue una realidad; la escasa población y abundancia de tierras facilitó que durante los siglos XVI y XVII hubiera grandes migraciones, las cuales se distribuyeron por todo el continente, desde el norte hasta el sur. A Brasil, específicamente al Estado de Rio Grande do sul, llegaron principalmente portugueses, además de alemanes, italianos y polacos, que trajeron a la cultura local las costumbres europeas (Stoltz, 1997). Los inmigrantes europeos en Rio Grande do Sul, en su mayoría, se hicieron grandes hacendados, ganaderos y latifundistas; debido al alto número de cabezas de ganado que se criaban de forma salvaje en su territorio. Esta cultura ganadera se encuentra presente actualmente, representada en las costumbres culinarias, principal- 
mente en el conocido churrasco y otras comidas del día tras día que se preparan con carne, tradición que frecuentemente sorprende a los actuales inmigrantes hispanoamericanos.

En el proceso de migración se da, de forma simultánea, un proceso de aprendizaje de nuevos significados y habilidades. La extrañeza inicial entre los significados de la cultura de origen y los de la cultura local se llamada "choque cultural", siendo el sentimiento más frecuente que vivencia el inmigrante, y puede ser evaluado por el grado de incertidumbre que éste tiene después de su llegada a otro lugar. De esta problemática se deriva el mayor dilema del inmigrante, que consiste en la tensión entre el empeño por una mayor adaptación sociocultural y la preservación de la identidad con su país de origen (Mota, Franco y Motta, 1999).

\section{Migración e identidad}

Al hablar de identidad, se marca una diferencia entre la identidad considerada como individualidad y como categoría social. Los orígenes de las posturas actuales sobre el tema permiten comprender las diferencias, así como asumir una posición sobre las propuestas que algunos autores hacen de ella. Para Rodríguez (2004), "la identidad de un sujeto nunca es un atributo constitutivo primario del mismo, sino una propiedad derivada de otras: la simetría y la transitividad (al modo como los gorilas que estudiaron Varela y Maturana se identificaban, cuando un círculo pintado era "pintado en sus frentes" reconociendo su imagen en un espejo). Así pues, la identidad es un término contextual, pues no es ni sujeto ni predicado, sino la conexión entre ambos" (p. 5).

En la psicología del desarrollo (Papalia y Old, 1997), la identidad es trabajada dentro de la comprensión de la personalidad, siendo así un componente de ésta. Inicialmente propusieron cuatro perspectivas para el estudio de la identidad: psicoanalista, social, cognoscitiva y de género. Más tarde se incluyen otros conceptos de identidad: nacional, étnica y cultural, a partir de los cuales se comprenden otras dimensiones construidas principalmente desde las relaciones sociales.

En la psicología social cognitiva norteamericana, la identidad se ha estudiado desde los papeles desempeñados y desde la formación del autoconcepto (Myers, 1999) trabajados por profesionales interesados en explicar la personalidad y la identidad. Son generalmente profesionales de la salud, como médicos, neurólogos y fisiólogos; más tarde, fueron los psicólogos formados en el área de la salud quienes continuaron por esta misma vía (Linares, 1996).

El conjunto de tensiones, interacciones e interdependencias que emergen en el nicho ecológico constituye una autoorganización espontánea a la que Morin (1992) denomina eco-organización. Para el autor, la identidad es un proceso de auto-organización que se mantiene gracias a la creencia en la transformación; así, las personas cambian sin perderla. Esta idea de transformación está dada por la conciencia de la vida y de la muerte, así como una concepción mitológica, y como una conciencia subjetiva de que existe una vida después de la muerte.

La sociedad y la individualidad son, al mismo tiempo, dos realidades antagónicas y complementarias. Antagónicas porque la sociedad, que es organizada por hombres relacionados jerárquicamente por períodos transitorios, limita la individualidad ya que cada hombre debe interactuar con el medio y con otras personas (Morin, 1992). A su vez, son complementarias porque los hombres van imponiendo sus propios intereses, mediante el uso del poder en el momento de colocarse en el vértice de la jerarquía. A través de los marcos y límites que impone la sociedad el hombre debe moverse y expresarse.

Las relaciones étnicas y raciales han sido, a través de la historia, importantes tópicos en investigación social. Pero varios aspectos de estas investigaciones fueron abandonados o disfrazados en nombre de cierta preocupación de que estas diferencias entre grupos étnicos y culturales pudie- 
sen ser mal utilizadas para fines socio-políticos, puesto que el conocimiento generado en esta dirección fue utilizado para la persecución, exclusión o exterminio de grupos étnicos en diversas culturas.

Sin embargo, recientemente surgieron nuevos constructos y perspectivas de investigación en la búsqueda del entendimiento de las relaciones inter-étnicas. Uno de estos nuevos conceptos fue el de identidad étnica (Quintana y Vera, 1999); éste abarca las dimensiones de identificación, comportamientos, conocimientos, sentimientos y/ o preferencias étnicas. La manifestación o expresión de esa identidad étnica, de acuerdo con las investigaciones de Quintana y Vera (1999), puede ser prevista por factores del desarrollo así como por los actores presentes en el proceso de inserción en una nueva cultura mayoritaria. Las identidades étnica y racial son teorizadas como un amortiguador psicológico o estrategia de auto conservación para lidiar con los aspectos hostiles de la cultura mayoritaria como el prejuicio, la discriminación y el estigma social.

De acuerdo con Sebben (1999) el proceso migratorio posee la característica de pérdida de la identidad cuando el inmigrante se siente pertenecer a todos los lugares pero, al mismo tiempo, a ninguno específicamente. En relación con el sujeto que inmigra, su identidad puede considerarse como productora de transformaciones fortísimas, pérdidas profundas y reconquistas constantes, poniéndola en riesgo al ser separado de sus raíces. El inmigrante siente la necesidad de aferrarse a varios elementos de su hábitat natural y mantener activa la experiencia de ser él mismo, luchando constantemente por su autoconservación.

La migración es una de las circunstancias de la vida que expone al sujeto a una desorganización que requiere posterior reorganización, derivada de la búsqueda intrínseca del ser humano hacia la estabilidad. Sin embargo, este movimiento de reorganización no siempre acontece de la forma esperada por los inmigrantes. La pérdida de la identidad es un riesgo existente durante este momento migratorio, específicamente en la pri- mera etapa que constituye el choque cultural. No obstante, se cree que si la persona posee suficiente capacidad de elaboración (Sebben, 1999), tendrá capacidad para superar las crisis y esta experiencia asumirá el carácter de una resurrección en que renace con dos identidades aumentando su potencial creativo y saludable.

La identidad étnica puede facilitarse cuando grupos pequeños o individuos se vinculan con una red de apoyo para movimientos sociales minoritarios, puesto que la identidad étnica obedece principalmente a la percepción de pertenecer a un grupo determinado, diferente de la identidad de raza, biológicamente hablando (Oakes, Halsman \& Turner, 1994). La funcionalidad de la manutención de una identidad étnica, lo mismo que su proceso de construcción entre inmigrantes, debe ser analizada a través de la historiografía de su presencia en determinado medio, considerando los diferentes contextos.

La identidad étnica es una construcción cultural que se realiza en un período histórico, en donde grupos étnicos en situaciones reales se recrean constantemente, y la etnicidad es siempre reinventada para hacer frente a la realidad que muda (Constantino, 2000). Etnia es un término usado para definir cómo los grupos son caracterizados en términos de nacionalidad, cultura y lengua comunes. Es un sentido de identidad compartido, que puede, o no, estar basado en la geografía, la religión, la raza y la lengua. La raza, por otro lado, es definida como una categoría en la que las personas comparten trazos biológicamente transmitidos y que son socialmente significativos, como el color de la piel y la textura del cabello (Woolfolk, 2000).

Etnia, raza y nación son conceptos asociados con la producción del sentido y criterios de pertenencia, y se constituyen como soportes de procesos a través de los cuales se posibilita la construcción de fronteras entre aquellos que pertenecen y aquellos que no pertenecen a determinado grupo o población. Sin embargo, estas fronteras no solamente relacionan, aproximan, separan y/o diferencian grupos entre sí, sino que actúan de tal 
forma que posicionan socialmente los grupos representados (Meyer, 1998).

Los criterios o parámetros que se utilizan para determinar la pertenencia de alguien a determinado grupo son muy heterogéneos, frecuentemente ambiguos y maleables. Difieren contextualmente en el tiempo y en el espacio en que son puestos en funcionamiento. En general, hacen referencia a haber nacido o ejercido el matrimonio dentro de determinados grupos o territorios, compartir determinados idiomas, religiones y otras herencias culturales de conocimiento, presentar caracteres fenotípicos semejantes y otras particularidades de contenido de estas nociones que son de carácter predominantemente político (Meyer, 1998).

En el caso de los inmigrantes, no se puede hablar de construcción cultural en un nuevo país como si fuese idéntica a la producción en su país de origen. Pozenato (2000) ejemplifica esta situación cuando diferencia la cultura italiana de la cultura de raíces italianas (en el caso específico de Rio Grande do Sul). Se trata de un estilo de vida, actitudes, conceptos y hábitos que son diferentes de la cultura mayoritaria, al mismo tiempo que difieren de la cultura de origen. Esa diferencia es explicada por la relación de equilibrio entre la presión ambiental y la posibilidad de mantener la cultura.

La cultura no es estática, sino que constantemente se desprende de muchos de sus trazos y admite incrementos de otros sistemas culturales sin sacrificar su identidad, pues es esta la fuerza sustentadora de sus trazos propios y distintivos (Silva, 1998). La cultura puede también ser encarada como una forma de comunicación del individuo y del grupo con el macrosistema; es una forma de herencia, pero también un reaprendizaje mutuo de las relaciones profundas entre el hombre y el medio (Silva, 1998; Sarriera, 2000) que nos ubica en relación con aquello que no somos, de tal suerte que nos posiciona de diferentes formas, en diferentes lugares y con diferentes efectos. Etnia, raza y nación son marcadores sociales que están profundamente involucrados con estos procesos de construcción de diferencias e identidades culturales.

Por otro lado, todos estos términos son originarios de otras áreas del conocimiento, como la antropología, la sociología y la educación. Sólo recientemente pasaron a ser mejor teorizados e investigados por la psicología, principalmente la psicología social (Sabatier y Berry, 1996). Los estudios culturales, multiculturales, transculturales e interculturales en la psicología abarcan una inmensa gama de tópicos. Específicamente, en la psicología social se desarrolló en los últimos veinte años un campo disciplinar llamado psicología intercultural o transcultural, conforme señalan Sabatier y Berry (1996).

Este campo del conocimiento psicosocial enfocó los estudios dedicados a describir y comprender la influencia de los actores culturales en su desarrollo y comportamientos; influencia traducida en términos de la diversidad de conductas y comportamientos cotidianos estudiados en las costumbres en diversas partes del mundo (Sabatier y Berry, 1996). Un segundo foco de este campo de conocimiento consiste en el análisis de la adaptación psicológica de los individuos y grupos cuando cambian de cultura.

\section{Método}

\section{Participantes}

En esta investigación participaron 11 familias inmigrantes hispanoamericanas, que viven en la región metropolitana de Porto Alegre, escogidas intencionalmente a través del Servicio de Acogida al Inmigrante mantenido por la Parroquia de Nossa Senhora da Pompéia (Porto Alegre). Aunque las familias hayan sido contactadas a través de la Iglesia, esa vinculación no revestía necesariamente un carácter religioso. Participaron familias constituidas de dos a trece miembros, provenientes de países suramericanos (Uruguay, Co- 
lombia, Chile, Perú y Argentina), con un tiempo de pertenencia en Brasil entre dos meses y 12 años, cuya intención de salir del país fue migración permanente, independientemente del hecho de tener o no su situación legalizada por la legislación brasilera.

\section{Procedimiento}

A través de contactos telefónicos y personales establecidos con varias familias, once de ellas aceptaron participar de la investigación. La colecta de los datos se dio a través de entrevistas semi-estructuradas, realizadas en un lugar acordado con las familias (sus residencias o en las dependencias de la Iglesia), siempre con la participación del mayor número posible de miembros de la familia y dos de los investigadores. Los tópicos que orientaron la entrevista fueron: trayectorias migracionales, decisión de inmigrar, inserción en la cultura local, relaciones comunitarias, identidad y expectativas de vida.

Todas las entrevistas fueron grabadas y transcritas integralmente con autorización previa de las familias; tales entrevistas son identificadas en el presente trabajo por un número. A partir de los relatos obtenidos en las entrevistas, se realizó un análisis de contenido categorial, de acuerdo con el método propuesto por Clemente-Díaz (1992), con la intención de levantar los aspectos que caracterizan expresivamente el proceso migratorio.

El análisis categorial, según Clemente-Díaz (1992), permite "analizar contenidos y extraer informaciones, partiendo del material recogido en un soporte específico, siendo realizado científicamente, mediante procedimientos confiables, válidos y derivados de un conjunto de nociones teóricas determinadas" (p. 169). Las categorías permiten comprender la trayectoria del proceso migracional de las familias; a partir de esta comprensión, se obtiene una caracterización del proceso psicosocial de migración. Así, se configuraron en el análisis cuatro ejes categoriales básicos: identidad personal, identidad cultural, identidad étnica e identidad nacional.

\section{Resultados}

\section{Identidad personal}

Las familias entrevistadas mantienen una dimensión de su identidad en cuanto elemento personal. Esto pudo verse en expresiones que hacían referencia al gusto por el país de origen $y$, a su vez, el agrado por el país de acogida. Algunas veces, es posible que las personas logren una integración entre las maneras de sentirse, bien como un brasileño, bien como un miembro de otra nacionalidad. "Yo ya no me siento muy Chilena... me gusta más la gente de aquí, porque no me siento discriminada" (miembro de la familia 8). Esta frase refleja la percepción de discriminación más fuerte en el país de origen, probablemente por la posibilidad de establecer más claramente las distinciones entre los paisanos, mientras que estar en una cultura diferente, en donde todavía no se discriminan los estereotipos intra-culturales, hace más probable que las diferencias sean menos reconocidas, generándose así un sentimiento de pertenencia al gran grupo.

Por otro lado, se observa la identidad cultural como una fuente de gratificación y de posibilidad de sentirse diferente, de mostrar a la comunidad de acogida que, si bien existe una adaptación al nuevo lugar, también se conserva una identidad que es propia. Esto se refleja por ejemplo en el orgullo por el lenguaje y las tradiciones del país de origen. Expresiones en este sentido son: "Mis compañeros piensan que yo soy mucho más educada que ellos porque sé hablar dos idiomas" (miembro de la familia 3).

\section{Identidad cultural}

La identidad cultural, orientada principalmente a las costumbres que comparte la mayoría de las personas de un país y/o región, tiene expresiones en aspectos como la música, el folclore, la tradición culinaria y la literatura costumbrista. Los inmigrantes perciben estas diferencias de forma puntual y específica o como un extrañamiento poco identificable. Por ejemplo: “Aquí es muy 
diferente para quien viene de otro país... las costumbres, la cultura..." (familia 2); "cuando entra la nostalgia, en ese momento, me pongo a escuchar mis músicas... músicas que allá ni escuchaba”... (familia 5); "¿puedes creer que aquí fue que sentí ganas de aprender tango? porque en Uruguay, que se baila mucho tango ni me gustaba. Fue cuando vine aquí y escuchaba el tango, que me daba nostalgia y así quise volver para rescatar mi cultura" (familia 7).

Las diferencias entre las costumbres locales y costumbres de origen relacionadas con los límites y normas de convivencia también son referidas como elementos de diferencia e identificación cultural. “Allá en Perú, todo es más rígido, los padres de uno le dan menos permiso para salir... pero a veces aquí se confunde libertad con libertinaje y lo puede llevar a uno a caer en la..." (familias 9 y 11). En este relato se refleja una preocupación por perder las normas que se traen; la diferencia y aceptación de la nueva cultura puede ser percibida como peligrosa, en el sentido de llegar a perder inclusive los patrones morales, o a no encontrar modelos con los cuales identificarse de la cultura de acogida que faciliten su adaptación a las costumbres locales.

\section{Identidad nacional}

En la identidad nacional se consigue observar que los rituales y las celebraciones del país de origen están presentes entre los inmigrantes. Este tipo de identidad invita a la congregación de estos grupos en ocasiones especiales para conmemorar fechas significativas que refuerzan el sentimiento de pertenencia e identificación colectivas. Reflejo de esto se observa en el siguiente relato: "Los peruanos siempre nos reunimos para festejar nuestras fiestas nacionales; así como aquí celebran el 7 de septiembre, nosotros también tenemos nuestro día patrio" (familias 9 y 11).

La identidad nacional se acentúa cuando los inmigrantes hacen distinciones entre las costumbres, sentimientos y gustos que les generan el de origen y el de acogida. Un extrañamiento de la alimentación, las modas, el clima, por ejemplo, siempre tiene al país de origen como punto de comparación y de referencia, haciendo que las diferencias entre éstos sean percibidas con mayor o menor intensidad. Como puede observarse: "en Argentina los ingredientes de las comidas son muy parecidos, pero la forma en que se cocinan son muy diferentes. Allá tenemos menos variedad de comida en una refección... hay otras cosas con las que casi no me acostumbro, como por ejemplo el clima, aquí se siente la diferencia en la piel" (familia 10).

Parece que cuando las condiciones de vida en el país de origen son más precarias que en el país de acogida, la percepción de estas diferencias se disminuye, y en algunas situaciones puede inclusive vivenciarse como mucho mejores: "Yo sinceramente no me considero chileno, porque ser chileno no ayuda, estorba.... me gusta mucho la gente de aquí, aquí todos me hablan, me tienen paciencia..." (familia 1). Sin embargo, este diálogo aparece solamente en una familia de todas las entrevistadas y sobresale de las otras en las cuales lo que se observa más es un sentimiento de nostalgia y de identificación con la nacionalidad, que se refleja en la siguiente expresión: "Tu sabes que el país de uno es parte de uno. Parece que siempre está faltando un pedacito de uno" (familia 4). La diferencia entre la sensación de bienestar en el país de acogida y la nostalgia que se observa en los dos diálogos anteriores puede manifestar la tensión permanente de los inmigrantes. Pueden maximizar recuerdos negativos o positivos del país de origen facilitando, en el primer caso, acercarse a la identidad del país que los acoge, mientras que podría hacer más lento el proceso de integración de identidades.

\section{Identidad étnico-racial}

En los grupos de inmigrantes, las características étnico-raciales son un patrón de identificación y de reconocimiento en el país de acogida. Los trazos, el color de la piel, la altura y, en algunas ocasiones, el acento en el lenguaje cuando oyen hablar en castellano en la calle son indicadores para la identificación en los grupos. La identidad étnica, además de ser individual, es también un 
elemento de pertenencia grupal, siendo así un factor de agrupación nacional. "Cuando paseamos por el 'brike", podemos reconocer a nuestros paisanos. Rápidamente uno se da cuenta quienes son, porque uno se reconoce solo al verse" (familia 1). Este reconocimiento por los trazos físicos y por el acento al hablar son aspectos de unión cultural e intercultural, el idioma español, independientemente del país de origen, facilita en los inmigrantes mantener vivos los vínculos hispánicos en Brasil.

\section{Discusión}

Existen aspectos impuestos que constituyen las dimensiones de la identidad; algunos de ellos pueden ser excluidos, modificados e inclusive negados. Este sería el caso de la dimensión de identidad racial, cuyas características son de origen biológico, pero que debido a los avances de la ciencia pueden ser modificadas, como el caso del cantante negro que se volvió blanco; de la identidad sexual, también ligada directamente a la biología y a la genética, pero cuyas características pueden ser modificadas quirúrgicamente en su expresión externa y, finalmente, de la identidad nacional, a la que puede renunciarse pero que no modificará con ello el lugar de nacimiento de la persona que lo hace.

Otras dimensiones de la identidad son asumidas y adquiridas, como la social, la étnica, la religiosa, la cultural, la social y la de género, que son formadas-constituidas por la identificación con ellas y la distinción entre ellas.

Puestas las definiciones-conceptos de varios autores y, principalmente, de varios tipos de identidad, cabe entonces la siguiente reflexión: ¿tene- mos una identidad o tenemos múltiples identidades? Desde el paradigma ecológico contextual, las personas tienen una identidad que está conformada por varias dimensiones y varias relaciones contextuales; la persona es un todo y también es una parte que representa ese todo; así, a través de las dimensiones de identidad nacional, étnica, cultural y personal, el individuo trae consigo lo que es como una totalidad. $Y$ aquí entonces vale la pena retomar la identidad como un acto de distinción; una distinción que, según Bateson (1999), hace la diferencia.

Es decir, es aquella parte del ser que permite distinguirse del todo, pero que hace parte del todo. Así, cuando se traza la distinción, al mismo tiempo surge la semejanza. Se focaliza la dimensión individual y se deja como plano de fondo la dimensión social, o viceversa. Y lo que hace la diferencia es que en esta concepción no queda nada oculto, nada por detrás; todo se puede localizar en el mismo plano y todo tiene la misma posibilidad de ser. No hay presupuesto de identidades ocultas; lo que vale aquí es lo presente. ¿La identidad del inmigrante tendría, en consecuencia, características diferentes a las discutidas hasta el momento? Se podría decir que lo que diferencia o distingue la identidad del inmigrante es la posibilidad de agregar elementos para enriquecer su propia identidad, al tiempo que puede ofrecer a la comunidad de acogida elementos para las personas interactúan con él, pues el intercambio cultural es primordialmente relacional.

\section{Referencias}

Bateson, G. (1999). Una unidad sagrada: pasos ulteriores hacia una ecología de la mente. Barcelona: Gedisa.

2 El brike es un mercado de pulgas que funciona los fines de semana en una zona céntrica de Porto Alegre en donde trabajan, además de brasileños, personas provenientes de países latinoamericanos, vendiendo artesanías típicas de los países de origen. 
Clemente-Díaz, M. (1992). Métodos y técnicas de investigación. Madrid: Eudema.

Constantino, N. S. (2000). Italianidade(s): imigrantes no Brasil meridional. En: Carboni, F. y Maestri, M. (eds). Raízes italianas do Rio Grande do Sul: 1875-1997. Passo Fundo: UPF (pp. 65-80).

Klein, H. S. (1999). Migração internacional na história das Américas. En: Fausto, B. (ed). Fazer a América. (pp. 13-32) São Paulo: EDUSP.

Linares, J. L. (1996). Identidad y narrativa. Barcelona: Paidós.

Meyer, D. (1998). Alguns são mais iguais do que outros: etnia, raça e nação em ação no currículo escolar. En: Silva (ed). A escola cidadã no contexto da globalização (pp. 369-380). Petrópilis: Vozes.

Morin, E. (1992) El paradigma perdido: ensayo de bioantropología. Barcelona: Paidós.

Mota, E.; Franco, A.; \& Mota, A. (1999). Migração, estresse e fatores psicossociais na determinação da saúde da criança. Psicologia, reflexão e crítica, 12 (1). pp.119-132

Myers, D. (1999), Psicología social. Rio de Janeiro: LTC Editores.

Oakes, P. Haslam, S. \& Turner, J. (1994). Stereotyping and social reality. Oxford: Blackwell.

Papalia y Old, (1997). O desenvolvimento humano. Porto Alegre: Artes Médicas.

Pozenato, J. C. (2000). A cultura da migração italiana. En: Carboni, F. y Maestri, M. (eds). Raízes italianas do Rio Grande do Sul: 18751997 Passo Fundo: UPF (pp. 115-120).

Quintana, S.M. \& Vera, E. M. (1999). Mexican American children's ethnic identity, understanding of ethnic prejudice and parental ethnic socialization. En: Hispanic Journal of Behavioral Sciences, 21:4, pp.387-404.

Rodríguez, J. Aspectos y problemas de la identidad cultural [versión electrónica]. En: Notas Sociológicas, No 3. Facultad de Ciencias Sociales, Universidad Nacional de San Juan, Argentina). Recuperado el 27 de junio de 2004, de: www.geocities.com/ Eureka/Mine/7903/antropo1.html

Sabatier, C. \& Berry J, (1996). Inmigración y aculturación. En: Bourhis, R. y Lelens, J. S. (ed). Estereotipos, discriminación y relación entre grupos. (pp. 217-241) Madrid: McGraw Hill.

Sarriera, J. C. (2000). Educação para a integração entre culturas e povos: da aculturação para o multiculturalismo (179-2020). En: Sarriera, J. C. (2000) (coord.) Psicologia Comunitária: estudos atuais. Porto Alegre: Sulina.

Sebben, A. (1999). Um estudo exploratório sobre intercâmbio cultural entre adolescentes brasileiros com contribuição da psicologia e da educação inter-cultural. Florianópolis. Dissertação de Mestrado- Centro de Filosofia e Ciências Humanas: UFSC.

Silva, P. (1998). Espaços para educação das relações inter-étnicas: contribuições da produção científica e da prática docente entre gaúchos, sobre negro e educação. En: Silva, L. (ed) A escola cidadã no contexto da globalização. (pp 381-398) Petrópolis: Vozes.

Stoltz, N. (1997) Ambiguous Identities: Central Americans in Southern California. Chicano/ Latino Research Center Working Paper, U.C. Santa Cruz, Spring.

Woolfolk, A. (2000). Psicologia da educação. Porto Alegre: Artes Médicas. 